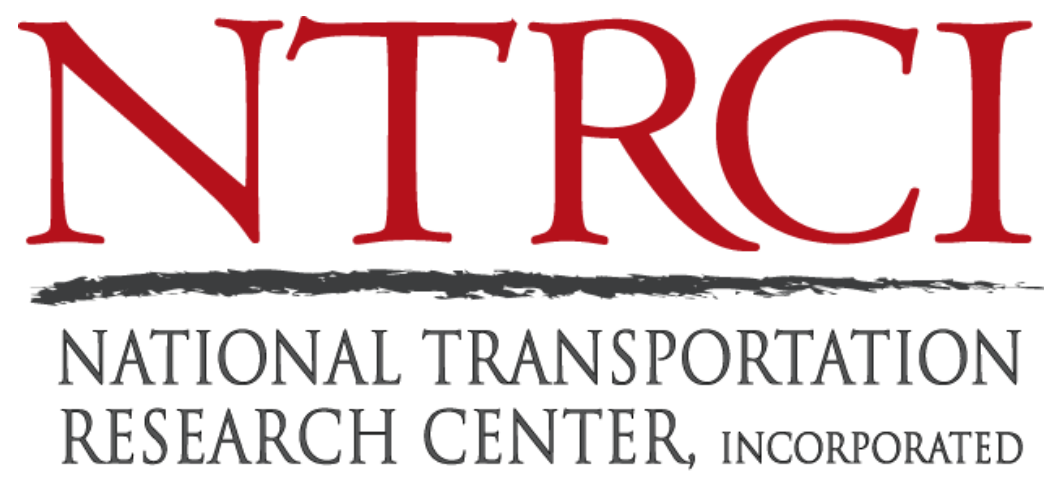

\title{
Project Galaxy - Sustainable Resource Supply and Environmental Implications
}

The contents of this report reflect the views of the authors, who are responsible for the facts and the accuracy of the information presented herein. This document is disseminated under the sponsorship of the National Transportation Research Center, Inc., in the interest of information exchange. NTRCI assumes no liability for the contents or use thereof.

Oak Ridge National Laboratory: Mark Downing Toyota Motor North America, Inc.: Robert Wimmer 


\section{Table of Contents}

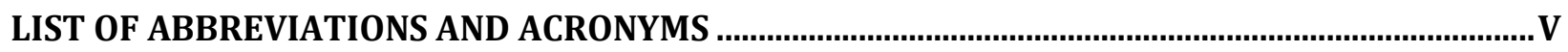

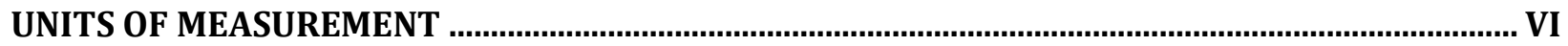

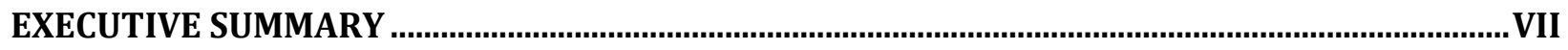

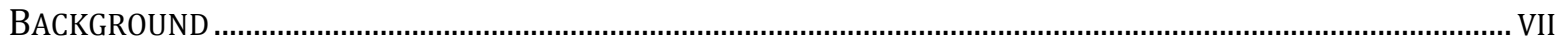

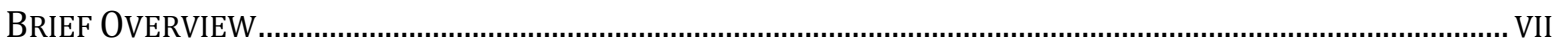

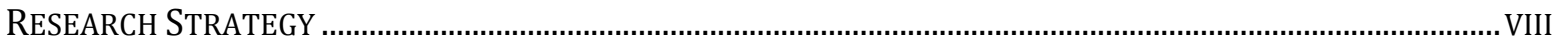

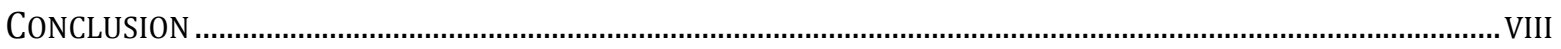

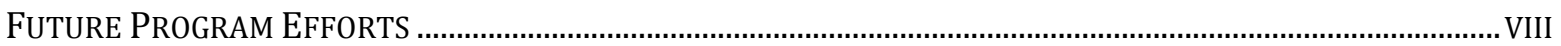

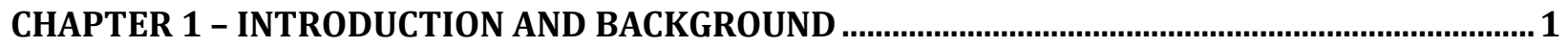

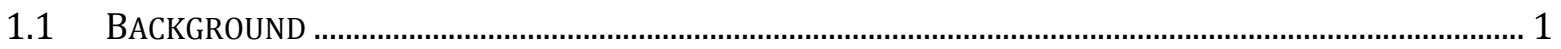

1.2 PROJECT DESCRIPTION............................................................................................................ 2

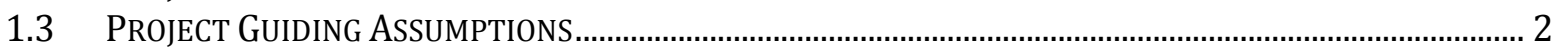

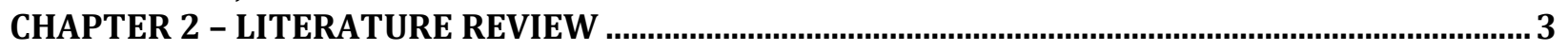

$2.1 \quad$ NEPA LITERATURE

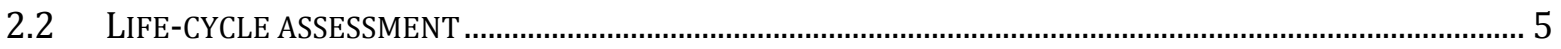

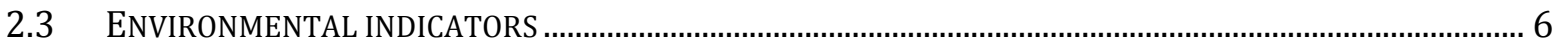

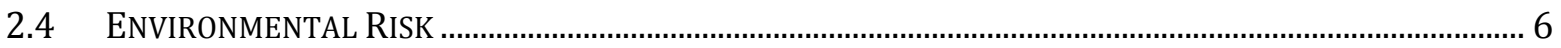

CHAPTER 3 - GOALS

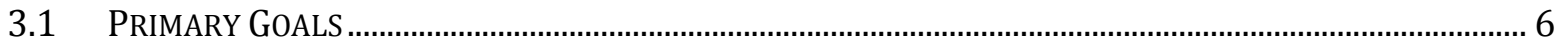

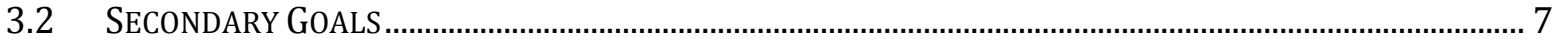

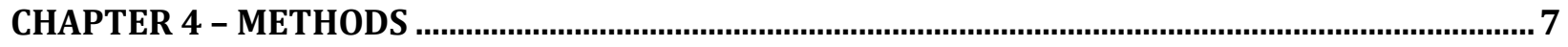

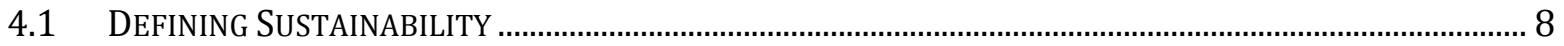

4.2 DEFINITION OF THE STUDY FRAMEWORK FOR ANALYSIS....................................................................... 8

CHAPTER 5 - ENVIRONMENTAL VARIABLES AND THEIR INDICATORS ........................................ 9

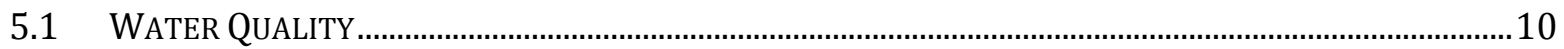

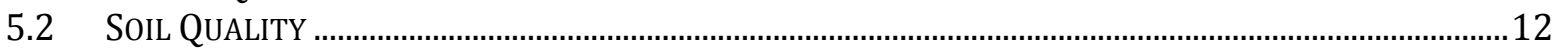

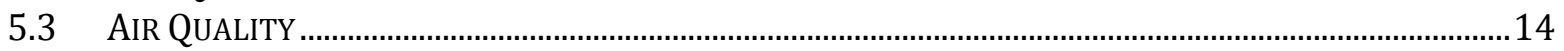

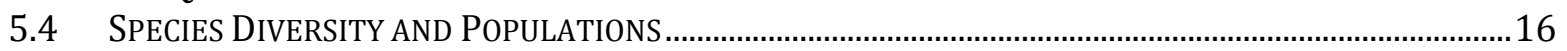

CHAPTER 6 - RISK ASSESSMENT AND RISK STRATEGIES

CHAPTER 7 - LIFE CYCLE ASSESSMENT WITH LIFE CYCLE INVENTORY ….................................. 18

CHAPTER 8 - ROLE OF NATIONAL ENVIRONMENTAL POLICY ACT (NEPA) ................................. 20

CHAPTER 9 - RELATING AND LINKING ENVIRONMENTAL COMPLIANCE (NEPA) AND

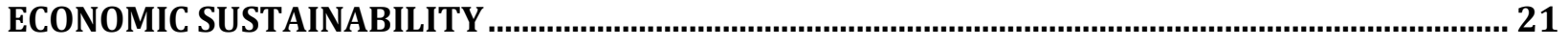

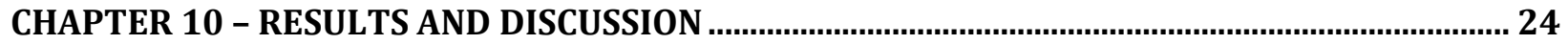

CHAPTER 11 - FURTHER RESEARCH

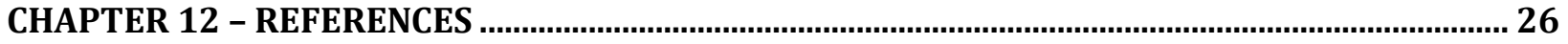




\section{List of Appendices}

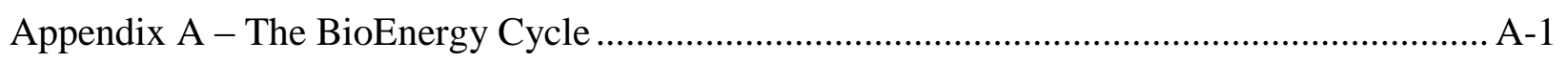




\section{List of Figures}

Figure 4-1. The BioEnergy Cycle. (ORNL 98-746/abh). See Appendix A................................. 9

Figure 5-1. Average Annual $\mathrm{PM}_{2.5}$ Concentration (WBEA, 2011) and (Env Canada 2011)...... 16 Figure 7-1. Multifunctional process showing several inputs in the form of resources consumed, in addition to several product outputs A and B (ILCD, 2010, page 73)................................ 19

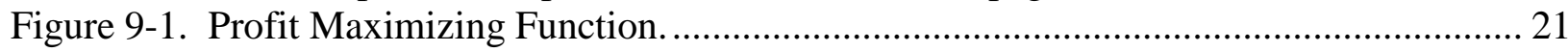

Figure 9-2. Multiple Benefits Maximization Function................................................... 22

Figure 9-3. This figure demonstrates the relative values over time as a result of dynamic modeling of a specific set of environmental amenities. This may be enhanced by specifying a geographic region or scale for inventory............................................23 Figure 10-1. Scope of the measurable attributes of environmental quality and quantity in an endto-end biorefinery operation. The red circle describes the focus of the environmental sustainability measures to include water, air, soil, and species populations and diversity

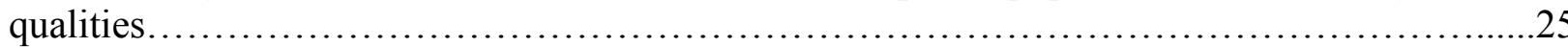




\section{List of Tables}

Table 5-1. Nitrate levels which are important to measure...................................................... 12

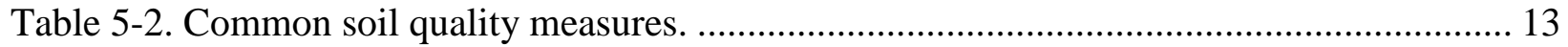

Table 5-3. Tillage induced reduction of decomposition of organic matter................................ 13

Table 5-4. National Ambient Air Quality Standards. ......................................................... 15 


\section{List of Abbreviations and Acronyms}

\begin{tabular}{|l|l|}
\multicolumn{1}{|c|}{$\begin{array}{c}\text { Abbreviation } \\
\text { or Acronym }\end{array}$} & \\
\hline CEQ & Council on Environmental Quality \\
\hline CRP & Conservation Reserve Program \\
\hline CERCLA & Comprehensive Environ. Response, Compensation and Liability Act \\
\hline CO $_{2}$ & Carbon dioxide \\
\hline CX & Categorical exclusion \\
\hline DOE & Department of Energy \\
\hline DOI & Department of Interior \\
\hline EA & Environmental Assessment \\
\hline EPA & Environmental Protection Agency \\
\hline EIS & Environmental Impact Statement \\
\hline FHWA & Federal Highway Administration \\
\hline FONSI & Finding of no significant impact \\
\hline ILCD & International Life Cycle Data \\
\hline ISO & International Standards Organization \\
\hline L & liters \\
\hline LCA & Life Cycle Assessment \\
\hline LCI & Life Cycle Inventory \\
\hline LCIA & Life Cycle Inventory Assessment \\
\hline MCL & Maximum contaminant level \\
\hline MCLG & Maximum contaminant level goals \\
\hline MN DNR & Minnesota Department of Natural Resources \\
\hline N & nitrogen \\
\hline NOx & Nitrous oxide \\
\hline NEPA & National Environmental Policy Act \\
\hline NOAA & National Oceanic and Atmospheric Administration \\
\hline NRC & Nuclear Regulatory Commission \\
\hline NTRCI & National Transportation Research Center, Inc. \\
\hline OAQPS & Office of Air Quality Planning and Standards \\
\hline PFD & Process flow diagram \\
\hline PM & Particulate matter \\
\hline RfD & Reference dose \\
\hline ORNL & Oak Ridge National Laboratory \\
\hline TAMU & Texas A\&M University \\
\hline TDEC & Tennessee Department of Environment and Conservation \\
\hline USDA & Volatile organic compound \\
\hline VOC & \\
\hline
\end{tabular}




\section{Units of Measurement}

\begin{tabular}{|l|l|}
\hline \multicolumn{1}{|c|}{ Unit } & \multicolumn{1}{c|}{ Meaning } \\
\hline $\mathrm{kg}$ & kilogram \\
\hline $\mathrm{Kg} / \mathrm{ha}$ & Kilogram per hectare \\
\hline $\mathrm{mg} / \mathrm{kg} / \mathrm{d}$ & Milligram per kilogram per dose \\
\hline $\mathrm{mg} / \mathrm{L}$ & Milligrams per liter \\
\hline$\mu \mathrm{g} / \mathrm{m} 3$ & Micrograms per cubic meter \\
\hline $\mathrm{ppb}$ & Parts per billion \\
\hline $\mathrm{ppm}$ & Parts per million \\
\hline
\end{tabular}




\section{Executive Summary}

Understanding what it takes to move from a corn-based liquid fuels industry to one that is cellulosic-based requires a complex transition over time. This transition implies, among other things, a shift from annual cropping systems considered under United States Department of Agriculture (USDA) policy as commodity crops, to perennial lignocellulosic crops that are herbaceous and wood-based. Because of changes in land use as well as biomass and other crop supplies, land-based environmental amenities such as water quality, soil health and tilth, air quality, and animal and avian species populations and their diversity change also. Environmental effects are measured as magnitudes (how much they are impacted), and direction of the impact (either positive or negative). By developing a series of quantitative and qualitative metrics, the larger issue of defining relative sustainability may be addressed, and this can be done at a finer detail of regional (scale) and environmental amenity-specific impacts. Although much literature exists about research relevant to specific environmental variables, there is no published, documented, nor research literature on direct application of environmental over-compliance with regards a "biorefinery."

\section{Background}

In existing large-scale nuclear, oil refinery, hydro, and electric projects, sometimes comprehensive strategies are understood regarding assessment of these environmental effects across all projects. The National Environmental Policy Act (NEPA) guides most of this work.

This is because most large-scale nuclear plants (for example) have a more homogeneous series of causes and effects. However projects like hydro (dam construction), and the lignocellulosic biorefineries have scale, size, and location that are so specific to conception, aspect, and construction, there is no generic tool (also called a Programmatic NEPA) or series of rules that will apply to environmental assessment as required by federal and state regulatory agencies. The framework and descriptions in this report will assist understanding how to define environmental amenities, and how to quantify and qualify expected impacts on them. More important, simply complying with environmental regulatory needs obviates consideration of measuring the extent to which environmental changes exceed compliance.

\section{Brief Overview}

Our three goals were to 1) understand and quantify bioenergy sustainability and some key environmental effects in a generic set of examples; 2) explain the effort and means to define and quantify specific qualitative environmental measures, and to determine a way to understand changes in these measures over time and what their implications might be; and 3) use these outcomes to evaluate potential sites in any geographic area. This would permit assessment of candidate locations, combined with an understanding of co-production of fuels, chemicals, and electric power, to interpret sustainability measures and the relationship between environmental sustainability and economic sustainability. 


\section{Research Strategy}

An extensive literature exists regarding defined environmental amenities, environmental regulatory and compliance requirements. Literature currently in press, or in review has recently afforded a greater understanding of a series of environmental indicators, sustainability indicators, and other proxies for societal indicators which will be referred to here. We propose a series of example environmental amenities, and ways to measure them quantitatively, relying on current literature to suggest bounds for "acceptability" of these quantitative measures. Finally, the results will be used in the future to frame a specific proposed facility given a series of assumptions such as biomass conversion technologies, and to evaluate the trade-offs between environmental and economic sustainability.

\section{Conclusion}

The process of determining environmental sustainability effects as a result of providing renewable energy is complex. We have only included in this report environmental effects as a result of producing biomass for the biorefinery, and the area represented by the footprint of the biorefinery itself. In doing this, we have defined critical environmental variables (water, soil, air, and flora and fauna) and discussed some measurable indicators used to quantify effects such as nitrate content, soil organic matter, air particulates, and avian species diversity, respectively. We also point out the need to perform specific sustainability risk assessments, and the need to continually evaluate the life cycle inventory with an accompanying life-cycle assessment. Only in this dynamic framework can environmental sustainability be determined, evaluated and assessed, and contrasted with economic sustainability goals of a firm or an industry.

\section{Future Program Efforts}

This report only includes a small portion of the entire cycle of the system to evaluate a lignocellulosic biorefinery. This life cycle assessment should stretch from the moment biomass is planted in the ground or harvested, to the time the emissions come from a tailpipe of some mode of transportation. Risk assessment strategies are necessary because you can evaluate the extent to which there is environmental over-compliance and it affords the ability to evaluate the economic cost of that over-compliance. The societal effects and the perception of compliance and overcompliance are very compelling motives to measure and evaluate. 


\section{Chapter 1 - Introduction and Background}

Many resource assessment and analysis questions have come from the U.S Department of Energy (DOE) about the potential biomass supplies for renewable energy markets in the U.S. The advent of the development of biorefineries to produce fuels, chemicals, and power has raised many more questions regarding technology readiness, markets for biorefinery products and coproducts, and the overall assessment of sustainable practices for business and the environment. This report addresses sustainability guidelines for the biorefinery and the biomass production systems.

\subsection{Background}

As early as 2004, the U.S. Department of Energy was asked to answer the question whether there would be biomass resources by 2030 that would replace 30 percent of the petroleum needs in the U.S. This would amount to about one billion tons of biomass feedstock available in the U.S. from a variety of resources, either currently existing, or that could be produced. The answer was that given a detailed series of assumptions, there would be roughly 1.3 billion tons of biomass feedstock to satisfy the need (Perlack, et al., 2005).

A recent completion of an update on this report (U.S. DOE, 2011) is valuable because it provides a spatial, county-by-county inventory of primary feedstocks, provides price and available quantities (supply curves) for the individual feedstocks, and represents a more rigorous treatment and modeling of resource sustainability.

The lignocellulosic ethanol biorefinery industry in the U.S. is currently in rapid and diverse stages of growth that include significant federal, state, and private investment in research and demonstration at different scales. There are many suggested feedstocks to convert through a number of different processes in a biorefinery to any of a number of different fuels, with significant co-product supplies as potential benefits. It is obvious that the U.S. is endowed with significant land resources and a diversity of agricultural and forestry wealth that will contribute to a successful addition to the liquid fuels supplies from sources other than fossil, or corn-based fuels.

To understand the transition from a traditional corn-based ethanol industry to a lignocellulosicbased ethanol, more commonly referred to in the U.S. as "the biorefinery," we necessarily imply many changes in fundamental agricultural operations, and changes in types of fuels produced and associated market economic effects, and changes in environmental effects. These environmental changes and effects, more commonly referred to as sustainability issues, are the focus of this project. Specifically, there are effects which are identified and quantified such as water quality and quantity, soil quality and implied health, air quality effects, and species diversity and populations. A great deal of effort is currently being studied about environmental or sustainability indicators, their identification, and quantification. 


\subsection{Project Description}

This project restricts its focus to major environmental effects, and seeks to understand magnitudes of some more general effects, and the direction of those effects, whether positive or negative. We also clearly define what sustainability means in the context of any potential geographic area of investigation, and describe a generic system which can be used to analyze any of a number of potential lignocellulosic feedstocks, and a variety of biorefinery conversion systems for liquid fuels production. This paper does not investigate eventual fuels end use and subsequent implications, and does not consider technology innovation, but does encompass the process from lignocellulosic crop production through the entire supply chain of biomass delivered to a conversion facility. This includes harvesting, preprocessing, storage, additional processing, and transportation. This report provides a framework whereby technology managers may understand the historical bases for measurable environmental variables, regulation of these effects, and potential legal implications of their actions. In addition, we identify a stream of potential non-market values which are not currently calculated in an industry's production function.

There have been many investigations of the effects of constructing large federally funded facilities for energy production and their related systems. Several examples in the literature are chemical and fuel refineries, nuclear weapons stockpiles handling and management, nuclear power facilities, hydropower and dam facilities, and wind, solar, and clean coal facilities. There may be generic or programmatic analyses of certain facilities such as for clean coal or nuclear facilities because they are more similar, one facility to another. They may be harder to analyze such as hydropower because of the diversity of environmental effects, differences in scale, and breadth of the geographic locations, and potential effects. Corn-ethanol refineries are as simple as oil refineries to examine, but lignocellulosic biorefineries are inherently more complex because there are multiple feedstocks, and multiple effects on the diversity of production regimes for those feedstocks. There are currently no commercial biorefineries operating in the U.S. at the time of publication of this document.

\subsection{Project Guiding Assumptions}

The following are a list of assumptions used throughout this study. They are important in framing any major endeavor such as this.

- transition from corn-based ethanol production to lignocellulosic-based ethanol production, not to exclude current or increased corn-based production

- consideration of the entire system from cropping to emissions from fuel combustion could have been included in the scope of this project, but will be investigated in the future

- sustainability is the concept, and the commercial biorefinery is entity, and these are both the focal point of this paper 
- identification of relevant environmental variables is key to defining sustainability

- measurement of environmental variables and identification of existing baseline parameters are crucial to scaling the relevance of them

- there is a need to understand and enumerate compliance in an environmental sense (minimum sustainable levels) along a continuum toward exceeding compliance (NEPA compliance process)

- segmentation of input/output choices combined with environmental parameter measurement will permit evaluation of options and trade-offs as well as construction of risk measures as a result of making biomass and fuels production decisions

- final result should be a profile of attributes that are measured and desirable for the entire integrated biorefinery system and considered in a dynamic sense

\section{Chapter 2 - Literature Review}

The sources of literature critical to understanding this project were those pertaining to National Environmental Policy Act (NEPA) law, rules, and regulations. Guidance in literature and through case studies was used to understand the appropriateness of establishing a set of procedures known as a "programmatic NEPA" whereby explicit assumptions were made about the homogeneity of projects' size, scale, location, and process. In this way, NEPA procedures could be carried out more efficiently, rather than examining each part of a development project as if it were the first time - which are better known as site-specific or project level NEPA assessments.

Additional literature below documents life-cycle assessment, specific environmental indicators, and environmental risk.

\subsection{NEPA Literature}

The NEPA area of literature includes references and guidance on regulations and policy, tools for measurement and evaluation, a solid body of references on lessons learned from NEPA experience, many other training manuals, and presentations. NEPA requires federal agencies to integrate environmental values into their decision-making processes by considering the environmental impacts of their proposed actions and reasonable alternatives to those actions (EPA, 2012). This process, known as the "NEPA Process", consists of an evaluation of the environmental effects of a federal undertaking including its alternatives. There are three levels of analysis: categorical exclusion determination; preparation of an environmental assessment/finding of no significant impact (EA/FONSI); and preparation of an environmental impact statement (EIS) (EPA, 2012).

In the case where no federal funds are used to invest in a project, individual State EPA rules, regulations and guidelines will influence environmental management and corporate strategy. 
Sometimes, these state EPA rules and regulations will be more stringent, and vary from state to state. A good example of renewable energy project state regulation may be seen in the case of Minnesota (MN DNR, 2012) where an Environmental Review is conducted to inform project decision makers about effects and measures that can be taken to avoid adverse environmental effects.

Current literature distinguishes between a "programmatic" environmental impact statements (EIS) and a "project level” EIS. "Programmatic NEPA analyses can reduce or eliminate redundant and duplicative analyses and effectively address cumulative effects" (CEQ, page 35, 2003). "Agencies rely on programmatic or broad-scale analyses to focus the scope of alternatives, environmental effects analysis, and mitigation in subsequent tiered levels of documentation" (CEQ, page 38, 2003).

Project level NEPA analyses are compliant because they emphasize a specific project site and circumstances, and are concerned only with the specific footprint or area being considered. Hydropower projects are a good example because they are very specific with respect to location, size, and potential environmental effects. There are few programmatic NEPA documents, rules, or guidance for hydropower projects.

Chemical weapons facilities mainly deal with stockpiles of materials and subsequent repurposing for energy, or simply the destruction of these weapons. They are covered by several published programmatic NEPA documents and procedures. Clean coal facilities traditionally have been guided by programmatic NEPA documents, as are some wind projects and petroleum refineries. The U.S. DOE has assessed natural gas and transmission lines and have programmatic guidance but some of this programmatic guidance does not necessarily deal with some specific issues such as exact scale and location.

In the case of nuclear power plants the Nuclear Regulatory Commission (NRC) guides the relicensing process. There are certain guidelines that are more programmatic in nature, although there are some site-specific issues that need to be dealt with. One specific example is specific fish populations that might be affected by water temperature variation from cooling tower water released into nearby bodies of water. The NRC relicensing EIS documents contain more than 90 issues that need to be considered and all but about 20 of them are generic at national level, while others will be addressed in a site-specific EIS. Programmatic guidance might lend an understanding of target capacity of nuclear power generation in the U.S., and if that target capacity were hit, one might look at implications to the market, and the redirection of power production efforts.

Corn ethanol facilities will have associated programmatic guidance because there is only one feedstock, and several co-products, common to all corn refineries.

In the case of the biorefinery, that is not the case. Although there are common elements among them that may be addressed in the future by programmatic guidance, these refineries by 
definition are facilities that receive input of various biomass feedstocks of a distinct quality. Biorefineries convert these feedstocks through technological processes such as biochemical, thermochemical, or a hybrid of the two into an array of co-products. Each of these co-products requires success in markets for the biorefinery to operate with engineering and economic efficiency.

A programmatic review would not be needed if all projects were studied on a site-by-site basis, but this would be inefficient and costly since projects have so many similar characteristics for environmental consideration. NEPA is important because federal agencies, state agencies, and firms and industries need to consider many potential effects. The environmental considerations provide NEPA processes frameworks for planning before the construction begins.

This is the point at which an understanding the concept of regulatory effects in federal and state cases moves from compliance (achieving an understood level of minimum or no environmental impacts) to moving beyond compliance, where environmental conditions are exceeded or improved through actions of a project. These might be considered mitigation effects, or simply called over-compliance, where clearly measured and verified improvements are made to different areas of the environment. This distinction is important because it is the measure of overcompliance firms and industries wish to understand, both in terms of natural resource effects, and economic costs. This understanding may be only achieved over time, while monitoring and assessing several economic variables, and business pro formae. This process is an intense, costly, and time-consuming effort including life-cycle assessments, and an understanding of relevant environmental indicators, and environmental risk measures. It demands site-by-site project level analysis and systematic dynamic study, and is costly.

\subsection{Life-cycle assessment}

One document was relied on heavily to provide general guidance when developing background for this project. The reference was published by the Joint Research Centre of the European Commission and is considered a handbook for businesses and the public, and describes how to conduct life cycle assessments to calculate environmental impact. It is called the International Reference Life Cycle Data System Handbook (ILCD, 2010).

The handbook provides detailed guidance on how to conduct a life cycle assessment to quantify emissions, resources consumed and the perturbations to the environment and human health that can be attributed to a product.

It has been developed by the European Commission's Joint Research Centre in cooperation with the Directorate-General for Environment. The ILCD Handbook is mapped into international standards ISO 14041 and 14044 and has been assembled through a series of extensive public and stakeholder consultations (ILCD, 2012). 
This whole handbook, has 7 guides: 1) General guide for Life Cycle Assessment (LCA) Detailed guidance; 2) General guide for Life Cycle Assessment (LCA) - Provisions and action steps; 3)Specific guide for Life Cycle Inventory (LCI) data sets; 4)Framework and requirements for Life Cycle Impact Assessment (LCIA) models and indicators; 5) Review schemes for Life Cycle Assessment (LCA); 6) Reviewer qualification for Life Cycle Inventory (LCI) data sets; and 7)Analysis of existing Environmental Impact Assessment methodologies for use in Life Cycle Assessment (LCA) (ILCD, 2012).

\subsection{Environmental indicators}

References relating to the description of environmental indicators, their definition, and their relationship to sustainability indicators are relatively scarce for the practitioner. One recent article describes the need to identify and characterize indicators to quantify benefits and costs associated with different bioenergy options and resource uses (McBride, et al., 2011). Another paper in process is "Indicators to support assessment of socioeconomic sustainability of bioenergy systems" (Dale et al.) Because there are many other frameworks proposed to organize a way to assess environmental damages, in cases of loss (Efroymson, 2004), these very specific case resources and references have been left out of the report.

\subsection{Environmental Risk}

The subject of environmental risk is crucial to understanding the ways in which firms, states, industries and federal practitioners understand risk calculations, (Fiorino, 1989). There is more literature available from a wide variety of recent journal publications, but Suter, (1993) is a resource for a great deal of the relevant literature.

\section{Chapter 3 - Goals}

There are three primary goals, and a series of secondary goals of this project. These focus on defining sustainability, and understanding the scope and scale of any environmental effects study. By providing a framework whereby any potential study project and site could be developed at the appropriate detail required, any project, whether federally funded or governed under state NEPA rules and regulations, specific environmental variables and their respective detailed could vary, and be identified.

\subsection{Primary Goals}

A primary goal of this report is to settle on the definition of sustainability that is generally accepted in the literature and in the current areas of environmental and ecological assessment. Another primary goal is to enable evaluation of environmental effects in any of a number of geographic areas, and include the ability to assess production of a diversity of biomass feedstocks (perennial or annual agricultural crops, and residues) or forestry production systems 
and resources. In addition, any of a number of different conversion technologies could be considered, whether biochemical, thermo-chemical, or a hybrid of the two.

A third goal is to suggest specific environmental variables in each of four categories: water, soil, air, and species diversity. In doing this, examples of variables considered will serve as examples of the kinds of qualification and quantification that might be required given development of a commercial biorefinery system. This would perhaps lead to a more comprehensive list of variables to be investigated given a particular series of identified site attributes.

It is necessary to determine starting levels of quantities, or examine an inventory of levels so that deviation from these levels could be determined over time. These are sometimes considered baseline measurements in some literature. Desirable biorefinery site attributes might be suggested as a result of this investigation. For example, a set of lower quality environmental attributes measured at a particular site might lend to rapid quality improvements simply by developing cropping production strategies, or specific land management activities. On the opposite end of the continuum might be the need to maintain a wetland because of the known fragility of that ecosystem that currently exists.

\subsection{Secondary Goals}

Secondary goals of this project were to suggest ways to evaluate economic sustainability and environmental sustainability of the biorefinery system, and to understand the trade-offs inherent under management strategies for development.

The final result of this investigation would enable practitioners and managers to evaluate a broad range of characteristics in making development decisions that would result in a certain level of sustainability and profit. Adequate understanding will entail consideration of legal requirements that exist under the current National Environmental Policy Act (NEPA) structure, as well as understanding what it would take to go beyond compliance to achieve environmental enhancements requiring little economic investment. In essence, the desired result is to help planners and investors to avoid making irreversible mistakes.

Secondary goals in this paper outline and define environmental parameters that would be examples and measures representing environmental sustainability across general categories such as soil, water, air, and population diversity. Given these suggested categories, specific parameters are defined here. If the variables are water quality, soil quality, air quality, and plant and animal or avian (bird) diversity, the parameters are dissolved oxygen content, soil carbon, air particulates, and species population and diversity.

\section{Chapter 4 - Methods}

Because published literature in the form of scientific papers and other reports was key to developing this paper, please refer to Chapter 2. Methods focus here on defining sustainability, and designing the study geographic footprint or area. 


\subsection{Defining Sustainability}

The sustainability literature is extensive on definitions. Federal agencies, special interest groups, and research scientists from all backgrounds differ as to the appropriate definition. We have selected the Report of the Brundtland Commission (1987) as the appropriate definition because it captures simplicity and breadth while catering to both environmental and economic issues. Brundtland states:

"Sustainable development is development that meets the needs of the present without compromising the needs of future generations to meet their own needs."

In adopting this definition, we imply that our working definition fulfills environmental, economic and social needs that vary in space and time. Brundtland further clarifies that an overriding priority should be given to the poor, and that technology and social organization impose limitations on the ability to meet present and future needs.

Other sustainability definitions are somewhat less complete for our application, and speak specifically of agriculture, or development, lack imprecision, or more boldly define sustainability by what it isn't.

Researchers have until now been unable to precisely parameterize sustainability because it has been a goal more to guide improvement relative to other options, and not a specific state or condition that has been defined (Wright, personal communication). However, scientists are considering a series of sustainability and environmental indicators that may help quantify not only the direction that relative sustainability is moving (better or worse) but also the magnitude of changes in sustainability (improved water quality through decrease in specific pollutants, or increased diversity of specific animal or avian populations).

\subsection{Definition of the Study Framework for Analysis}

The geographic basis for this study was to be only two specific areas: 1) the area where biomass was to be procured, and 2) the footprint of the actual biorefinery. Biomass production areas are known measurable environmental implications from these areas (Figure 4-1, red circle \#1). The other area, the biorefinery footprint is shown in in Figure 4-1, red circle \#2. These two areas would include the entire study and permit consolidation of the logistics supply chain for harvesting, handling, storage, transportation and processing of biomass feedstocks. The best pictorial description of these areas is shown in Figure 4-1. 


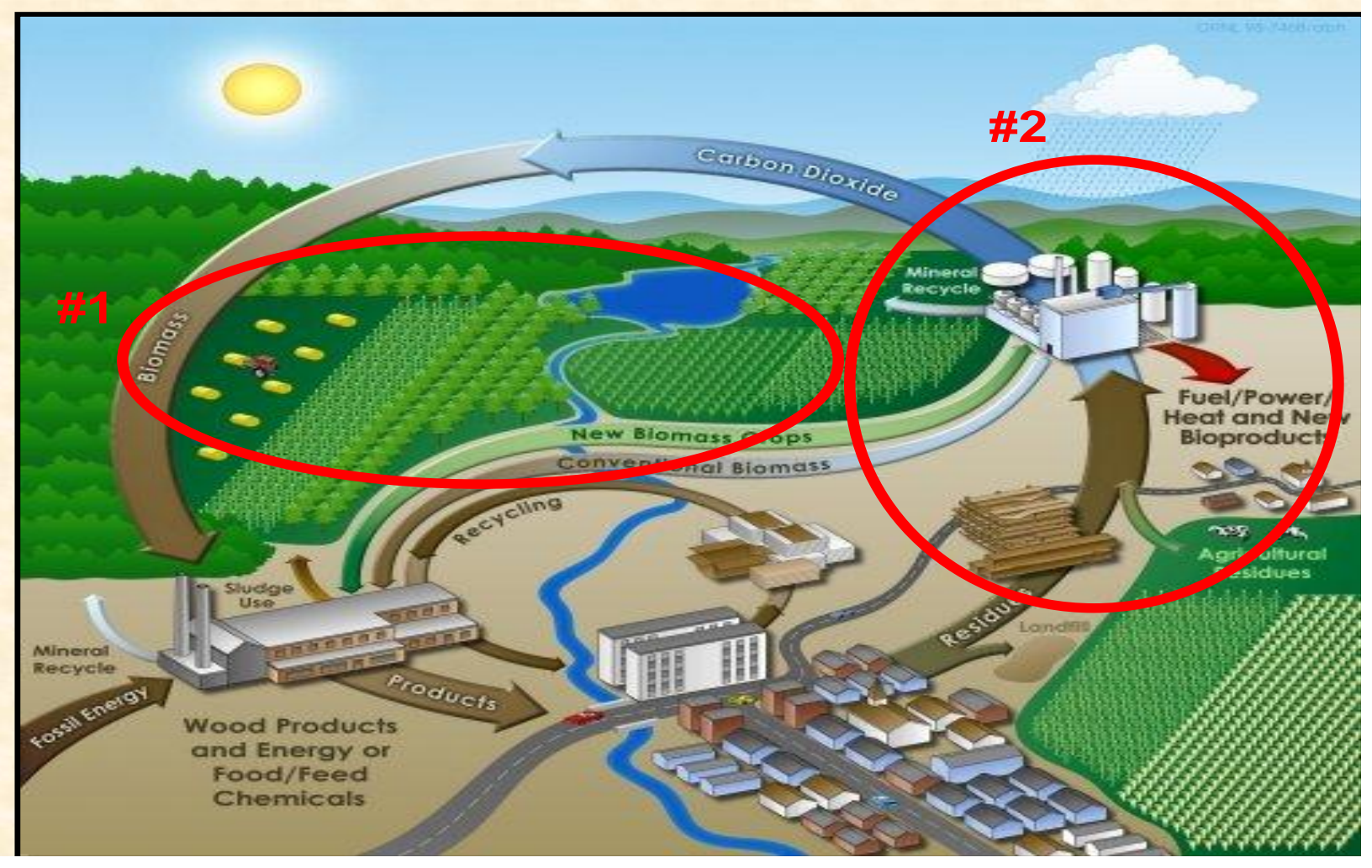

Figure 4-1. The BioEnergy Cycle. (ORNL 98-746/abh). Sustainable use of natural energy mimics the earth's seasonal variations and minimizes the emission of pollutants into the air, rivers, and oceans. Most of the carbon to create it is taken from the atmosphere and later returned to the atmosphere. The nutrients to create it are taken from the soil and later returned to the soil. The residues from one part of the cycle form the inputs to the next stage of the cycle. See Appendix A.

\section{Chapter 5 - Environmental Variables and their Indicators}

Detailed studies of individual environmental amenities at the general levels of water quality, soil quality, air quality, and species diversity were found and are summarized without including exhaustive detail. This paper focusses on the most important measurements of large categories of sustainability (soil, air, water, and diversity).

Water quality and water quantity are both excellent considerations in the case of water use, but water quantity (use levels) could best be measured in the biorefinery system using process flow diagrams (PFDs) that are available from engineering specifications. This consumption varies depending on the conversion technologies proposed, and since this level of detail is outside the scope of this paper, we chose water quality as an example. A combination of dissolved oxygen content, and nutrient content of water were selected for measurement and analysis (Smith, 1987).

A very detailed list of possible specific measurement science of specific soil qualities was enumerated in one publication to include such as things as earthworm count and content, subsurface soil organic matter, organic matter on the surface, and subsurface compaction levels are just four. Soil tilth and friability, crumbliness and sponginess, gully presence and visible 
erosion, soil water holding capacity (drought resistance), resistance to ponding or runoff from normal rainfall levels, soil color, soil $\mathrm{pH}$, and finally nutrient holding capacity was a twelfth characteristic of soil quality (University of Minnesota, 2001). Soil organic matter was considered a most important consideration of overall soil health (Bot, et al., 2005).

In the area of air quality in context of the biorefinery, one representative quality is particulate matter coming directly from processing and handling of biomass feedstocks. There are other volatile organic compounds (VOCs) as well as on overall consideration of ozone levels in the atmosphere, but it was decided from the standpoint of agricultural and processing systems at the biorefinery, particulate matter was the better measure.

Finally, a consideration of both plant and animal or avian diversity are important indicators of ecosystem health. For purposes of this investigation, overall plant biodiversity measurements, as well as understanding existing avian populations are important. Since it has never been decided in a particular type of ecosystem the desirable mix of species of plant or animal materials, overall diversity is an appropriate measure. This is done through population sampling, and identifying indicators in a particular geographic region that contribute to proliferation of these species in their current habitat. The literature in this area is more diversified and scattered, taking into account site-specific studies with very little reference to determination of preferred levels and goals of species diversity (Efroymson, et al., 2004).

\subsection{Water Quality}

Different agencies have different measurements and priorities for types of water quality measured and regulated for different uses. Some of these measurements are temperature, $\mathrm{pH}$, specific conductance, turbidity, dissolved oxygen, hardness, and suspended sediment (Swanson, 1965).

Oxygen in water is necessary for aquatic life, just as oxygen in air is necessary for human life. The concentration of dissolved oxygen is a single, easy-to-measure characteristic of water that correlates with the occurrence and diversity of aquatic life in a water body. A water body that can support diverse, abundant aquatic life is a good indication of high water quality. Dissolved oxygen content of water is easily measurable given current technology.

A related problem is an excess of nutrients in water. Large quantities of nutrients in water can cause excessive growth of vegetation. This excessive vegetation, in turn, can cause low dissolved oxygen as it decays

Nutrients in water include various forms of the chemical elements nitrogen and phosphorus - the same materials we apply as fertilizer to our lawns, gardens, and farms to foster the growth of plants. They have the same effect in water as they do on land, encouraging the growth of aquatic plants such as algae (floating or attached to rocks) and rooted macrophytes (e.g., water lilies). 
Without nutrients water would be sterile and not support aquatic life. Adding nutrients can be acceptable and even beneficial at times, as they increase the productivity of a water body. However, if we inadvertently add too much nutrients to our waters the growth of aquatic plants becomes excessive. This is known as cultural eutrophication.

Visually this can change the clarity and desirability of the water. More importantly, the plants eventually will die and their decay uses up oxygen dissolved in the water. Excessive aquatic plant growth is a leading cause in the depletion of oxygen needed for fish. The root cause, however, is too much nitrogen and phosphorus. Because they accumulate many things, including nutrients, lakes and reservoirs are most prone to cultural eutrophication.

The most common measures of nutrients are nitrate-nitrite nitrogen and total phosphorus, but much is often learned by measuring other forms such as total inorganic nitrogen, organic nitrogen, or soluble reactive phosphorus. These components are easily measured as well.

In the case of the bioenergy cycle, all of these measurements can provide different insight into the effects on the bioenergy cycle of biorefinery development. We provide a specific example of the complexity of this issue by illustrating nitrate loading.

$\mathrm{N}_{2}$ or nitrate nitrogen is important to monitor in drinking water because of human health effects. High nitrate content has also been correlated with higher volatile organic compounds (VOCs). Groundwater effects are studied because they represent an important source of drinking water for a significant portion of the population.

Nitrate loading in streams from agricultural production runoff causes dead zones in the Gulf of Mexico as a result of Mississippi River flow from fertilization of agricultural areas. The implications of this are detailed several publications, the most noteworthy being Dale (2010). The important points about nutrient loading are the causes of hypoxia, the fate of nutrient transport and sources, and the scientific bases for goals and management. It would be simplistic to suggest the majority of nitrate comes from agricultural runoff, but if agriculture is a significant portion of biomass production for the biorefinery, then it is crucial to consider.

Unlike temperature and dissolved oxygen, the presence of nitrate usually does not have a direct effect on aquatic insects or fish. Excess levels of nitrate in water can create conditions that make it difficult for aquatic insects or fish to survive. Algae and other plants use nitrates as a source of food. If algae have an unlimited source of nitrates, their growth is unchecked. Large amounts of algae can cause extreme fluctuations in dissolved oxygen. Photosynthesis by algae and other plants can generate oxygen during the day. However, at night, dissolved oxygen may decrease to very low levels as a result of large numbers of oxygen-consuming bacteria feeding on dead or decaying algae and other plants (TAMU 2003).

This example of nitrate effects demonstrates the complexity and magnitude of potential effects from the biorefinery plant, and industry development. 
A specific regulatory example is important to note. In 1974, Congress passed the Safe Drinking Water Act. This law requires EPA to determine the level of contaminants in drinking water at which no adverse health effects are likely to occur. These non-enforceable health goals, based solely on possible health risks and exposure over a lifetime with an adequate margin of safety, are called maximum contaminant level goals (MCLG). Contaminants are any physical, chemical, biological or radiological substances or matter in water (EPA, 2003)

The MCLG for nitrate is $10 \mathrm{mg} / \mathrm{L}$ or $10 \mathrm{ppm}$. EPA has set this level of protection based on the best available science to prevent potential health problems. EPA has set an enforceable regulation for nitrate, called a maximum contaminant level (MCL), at $10 \mathrm{mg} / \mathrm{L}$ or $10 \mathrm{ppm}$. MCLs are set as close to the health goals as possible, considering cost, benefits and the ability of public water systems to detect and remove contaminants using suitable treatment technologies. In this case, the MCL equals the MCLG, because analytical methods or treatment technology do not pose any limitation (EPA, 2003)

The Phase II Rule, the regulation for nitrate, became effective in 1992. The Safe Drinking Water Act requires EPA to periodically review the national primary drinking water regulation for each contaminant and revise the regulation, if appropriate. EPA reviewed nitrate as part of the Six Year Review and determined that the $10 \mathrm{mg} / \mathrm{L}$ or $10 \mathrm{ppm}$ MCLG and $10 \mathrm{mg} / \mathrm{L}$ or $10 \mathrm{ppm} \mathrm{MCL}$ for nitrate are still protective of human health (EPA, 2003)

Table 5.1 (EPA, 2003) presents a summary of nitrate levels which are important to measure. It emphasizes the detail and complexity of measuring and monitoring, explicitly for health effects.

Table 5-1. Nitrate levels which are important to measure

(excerpt from EPA, 2003, page 15)

Chemical

\begin{tabular}{|llllll}
\multicolumn{2}{l}{ Regulation (month/year) } & \multicolumn{3}{c}{ IRIS (year) } \\
MCLG & MCL & RfD & Cance & RfD & Cancer \\
mg/L & mg/L & mg/kg/ & r & mg/kg/ & group
\end{tabular}

48. Nitrate (as N) $\quad 10 \quad 10 \quad 1.624 \quad \mathrm{D} \quad 1.624 \quad \mathrm{NA}$

(1/91) (91)

24 RfDs for nitrate and nitrite, in $\mathrm{mg} \mathrm{N} / \mathrm{kg} /$ day, back-calculated from epidemiological studies on the basis of $0.64 \mathrm{~L} /$ day and a $4-\mathrm{kg}$ infant.

\subsection{Soil Quality}

Organic matter content of soil contributes positively to productivity and other areas of health of soils. Higher organic matter levels suggest the action of soil organisms that operate normally in soils to promote aeration, $\mathrm{pH}$ levels, breakdown and transition of sloughed root materials, and to the entire soil health status. Organic matter is one measure directly correlated to soil carbon, measures of which have become important both in terms of soil carbon and below-ground carbon sequestration. This sequestration is a central point in the carbon emissions argument with respect 
to the larger greenhouse gas and climate change discussions. Soil organic carbon is easily measured.

Table 5.2 demonstrates other soil quality measures commonly used in science and practice (University of Minnesota, 2001).

Table 5-2. Common soil quality measures

\begin{tabular}{|l|}
\hline Presence of earthworms \\
\hline Organic matter \\
\hline Organic surface residues \\
\hline Degree of subsurface compaction \\
\hline Tilth - friability \\
\hline Soil crumbling and easily cut \\
\hline No gullies and surface runoff \\
\hline Water retention \\
\hline No ponding from normal rain $\backslash$ fall \\
\hline Crop color (dark green) \\
\hline Soil pH \\
\hline Nutrient holding capacity \\
\hline
\end{tabular}

Soil organic matter content is evaluated differently than nitrate content in water because it is not regulated, but is an indicator of soil health. Organic matter is particularly important when crop production supplies biomass for biorefineries. More critical for the biorefinery footprint is soil contamination from industrial biorefinery processes, and wastewater runoff on soils on the plant site.

There are several ways to measure soil organic matter (Brady, 1974; Tisdale et al., 1975).

A specific example of tillage impact on soil organic measure is outline in detail in Bot (2005) and appears in Glanz (1995). Table 5.3 illustrates these effects.

Table 5-3. Tillage induced reduction of decomposition of organic matter

\begin{tabular}{|l|c|}
\hline Type of tillage & Organic matter lost in 19 days (kg/ha) \\
\hline Mouldboard plough + disc harrow $(2 \mathrm{x})$ & 4300 \\
\hline Mouldboard plow & 2300 \\
\hline Disc harrow & 1840 \\
\hline Chisel plow & 1720 \\
\hline Direct seeding & 860 \\
\hline
\end{tabular}

Source: Glanz, 1995

Although soil organic matter is a true indicator of soil health with impacts on crop productivity over time, (highlighting the sustainability issue) it is not the only measure, as mentioned in the introduction section. 


\subsection{Air Quality}

Particulate matter a regulated and important indication of air quality. Some particulate matter is considered invisible (and more harmful) than other more visible particulate matter such as sawdust and diesel exhaust. Particulate matter monitoring can indicate relative concentrations of several pollutants, and can be considered over the short term, or long term. Dispersion models use computer algorithms to predict the concentration in the air of pollutants from different sources, such as from industry and agriculture taking into account weather conditions, pollutant type, human or other activity, and weather parameters. Land use regression models characterize the spatial distribution of exposure in a specific location, or a region based on land use characteristics (San Francisco Department of Public Health, 2011).

For the particular case of the biorefinery, measurable particulate matter levels are expected in all areas of the operations from agricultural production through biorefinery day-to-day operations. This includes harvesting, handling, pre-processing, storage, transportation, processing, and feeding on a conveyance system. In addition, plant operation emissions are important to understand and measurements.

EPA measures and considers 6 common air pollutants. These are ozone, particulate matter, carbon monoxide, nitrogen oxides, sulfur dioxide, and lead (EPA OAQPS. 2008).

The EPA Office of Air Quality Planning and Standards (OAQPS) has set National Ambient Air Quality Standards for six principal pollutants, which are called "criteria" pollutants. They are listed below in Table 4. Units of measure for the standards are parts per million (ppm) by volume, parts per billion (ppb - 1 part in 1,000,000,000) by volume, milligrams per cubic meter of air $\left(\mathrm{mg} / \mathrm{m}^{3}\right)$, and micrograms per cubic meter of air $\left(\mu \mathrm{g} / \mathrm{m}^{3}\right)$.

Two species of particulate matter (PM) commonly referred to in the regulatory literature and guidelines are $\mathrm{PM}_{2.5}$ and $\mathrm{PM}_{10}$. Particles less than 2.5 micrometers in diameter are called "fine" particles. These particles are so small they can be detected only with an electron microscope. Sources of fine particles include all types of combustion, including motor vehicles, power plants, residential wood burning, forest fires, agricultural burning, and some industrial processes. This would include the biorefinery.

Particles between 2.5 and 10 micrometers in diameter are referred to as "coarse." Sources of coarse particles include crushing or grinding operations, and dust stirred up by vehicles traveling on roads.

Table 5.4 depicts the national ambient air quality standards as established by the 1990 Clean Air Act and its amendments. Only particulate matter levels are listed, although the complete reference table lists all six. 
Table 5-4. National Ambient Air Quality Standards

(EPA, 2008; http://www.data.gov/)

\begin{tabular}{|c|c|c|c|}
\hline \multirow[b]{2}{*}{ Pollutant } & \multicolumn{2}{|c|}{ Primary Standards } & Secondary Standards \\
\hline & Level & Averaging Time & Averaging Time \\
\hline $\begin{array}{l}\text { Particulate } \\
\text { Matter }\left(\mathrm{PM}_{10}\right)\end{array}$ & $150 \mu \mathrm{g} / \mathrm{m}^{3}$ & 24 -hour ${ }^{(5)}$ & Same as Primary \\
\hline$\left.\frac{\text { Particulate }}{\text { Matter (PM}}{ }_{2.5}\right)$ & $15.0 \mu \mathrm{g} / \mathrm{m}^{3}$ & $\begin{array}{l}\text { Annual (6) } \\
\text { (Arithmetic } \\
\text { Average) }\end{array}$ & Same as Primary \\
\hline & $35 \mu \mathrm{g} / \mathrm{m}^{3}$ & 24-hour (7) & Same as Primary \\
\hline
\end{tabular}

${ }^{(5)}$ Not to be exceeded more than once per year on average over 3 years.

(6) To attain this standard, the 3-year average of the weighted annual mean PM2.5 concentrations from single or multiple community-oriented monitors must not exceed $15.0 \mu \mathrm{g} / \mathrm{m}^{3}$.

(7) To attain this standard, the 3-year average of the 98th percentile of 24-hour concentrations at each population-oriented monitor within an area must not exceed $35 \mu \mathrm{g} / \mathrm{m}^{3}$ (effective December 17, 2006).

Data.gov and the Federal Government cannot vouch for the data or analyses derived from these data after the data have been retrieved from Data.gov.

The temporal nature of monitoring captures the essence of environmental sustainability although the matter is complicated. Monitoring over time is considerably more expensive, and the sampling and reporting protocols vary for the pollutant. When combined with other data and information from which there are correlations, a great deal can be learned about long-term effects on human health and the environment. Figure 5-1 shows ambient PM2.5 from Environment Alberta (Canada) for a specific case of continuous monitoring (Wood Buffalo Environmental Association, 2011). These PM2.5 levels are useful in evaluating policy standards or objectives, and for instituting new objectives for attainment. 


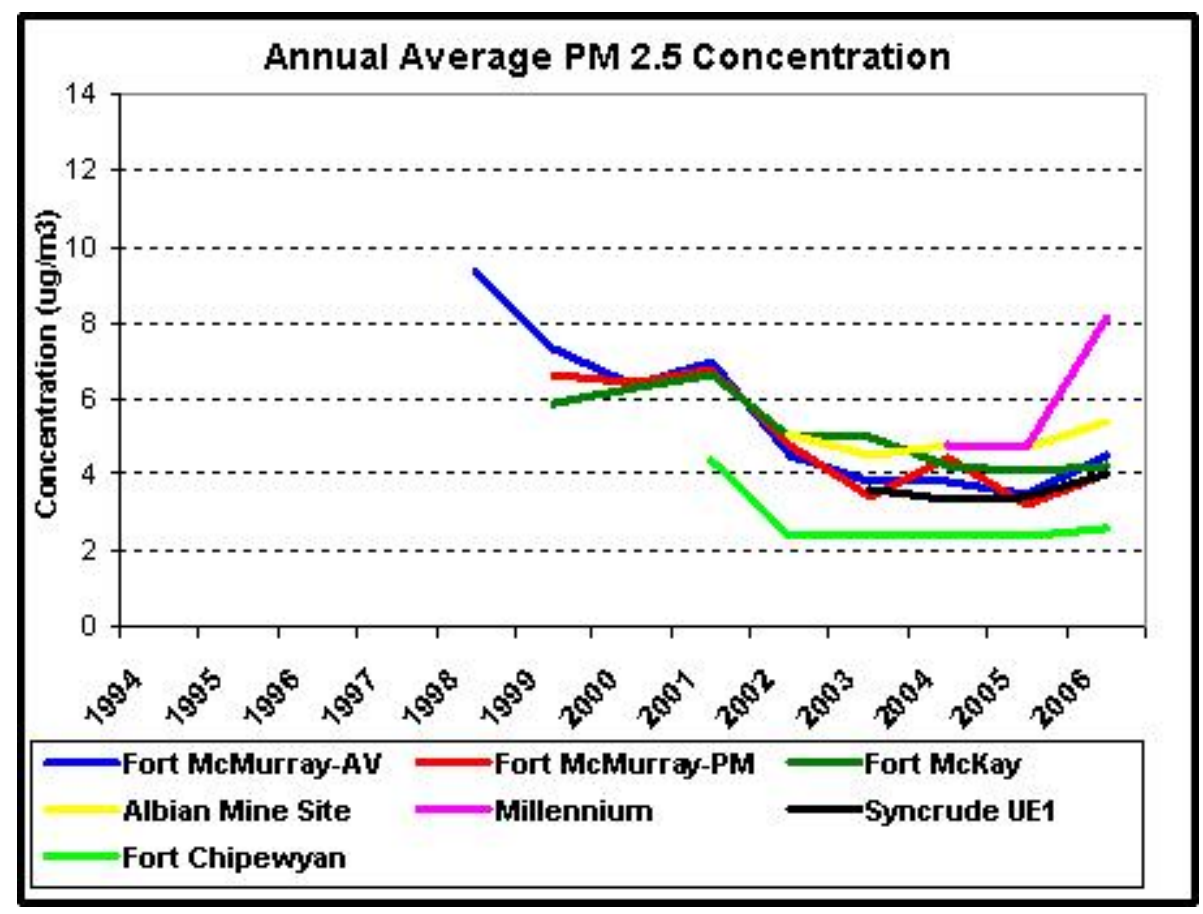

Figure 5-1. Average Annual PM2.5 Concentration (WBEA, 2011) and (environment Canada 2011).

The source of the materials is http://www.environment.gov.ab.ca/. The use of these materials by Mark Downing is done without any affiliation with or endorsement by the Government of Alberta. Reliance upon Mark Downing's use of these materials is at the risk of the end user.

Again, of all the air quality measures considered, particulate matter levels are considered critical for the biorefinery because they are important across the entire supply chain of operations beyond the scope of this study, and they are specifically regulated by EPA. State and provincial environmental regulatory agencies also have their own specific regulations and monitoring guidelines. States and provincial governments can be more restrictive than federal rules.

\subsection{Species Diversity and Populations}

The case for evaluation of sustainability of plant and animal populations, diversity of species, quality of ecological health, human use-value, and economic value of these species is complex and controversial. To simplify this, a description of NEPA investigation and reporting relating to wildlife and habitat, and two anecdotes are appropriate. Measuring species diversity can be challenging and complex.

If the definition of sustainability as stated on page 5 is our guiding principle, then there are key sustainable development objectives related to wildlife and plants to conserve these resources. Efroymson, et al., (2004) investigated an ecological framework for assessing risk from environmental degradation. For our work, we wish to discover a priori ways to evaluate the diversity and assess populations in a current state of the world, and then seek to establish environmental guidelines to achieve goals using tools. An assessment or inventory is an important tool to comprehend what exists at the outset, and a means to re-examine changes over 
time to evaluate how we are doing. Changes can be measured including the direction of the deviation, and the extent. The use of environmental indicators gives us ways to use proxies to assess these changes in the environment. Some indicators are native species at risk, plant diversity along streams, and the distribution and quantities of any bird, mammal, or plant species.

The NEPA process fully described on Chapter 8 consists of an evaluation of all environmental effects as a result of a proposed undertaking or action as well as including any alternatives. Initial screening documents normally include a checklist that responds to the basic overall simple questions, "What is the nature of the affected environment?" and "What are the environmental consequences of the proposed action?" This means for each and every inventoried item in the proposed geographic area of operation of the project, what is the environmental amenity, and what is the possible effect on that amenity. If the answer(s) are unknown, a risk assessment is required. If the answer(s) are known, then a plan for establishment of goals and objectives for maximizing the opportunity of maintaining that environmental amenity must be developed, and a plan for minimizing the effects on that particular population must be established.

Two pieces of anecdotal information are appropriate. In south central Iowa, establishment of 5000 acres of switchgrass was proposed on land that had been, or was currently under contract in the Conservation Reserve Program (CRP) of the United States Department of Agriculture (USDA). Although random informal surveys of bird populations was generally known and relayed by word of mouth, exact counts of songbird species were not known. A team of scientists and researchers embarked on a 3-month survey of bird species and revealed an extensive population of song and other birds. Although a great deal was known about the biology of the inventoried species, the action of establishing switchgrass in an intensive way on land that had been in the CRP Program for many years was not known. While the existing species of grasses were very similar to the proposed switchgrass, the effects of re-planting, harvesting time, and height of the mowing was not known. In this particular case, the appropriate question was "What species of songbirds were important to maintain, and were there other avian species that were important to maintain populations of as well, such as pheasants or quail for hunting in the fall?" In this case, it was rather a simplistic question, with a complex series of answers depending on what outcome on the environmental and ecology was desired.

In another example, a project proposed to build a liquid fuels manufacturing facility on an existing site that had been used for manufacturing other liquid fuels and chemicals. The site had been idle and unused for several years, but an initial inventory revealed holes in the ground that might indicate nesting for gopher tortoises which are protected under current environmental regulations in that particular state. Further investigation revealed no populations of these turtles; instead there was a population of a species of ground snake that was not protected, endangered, and for which there was little of interest from an ecological standpoint. In this example, the inventory was important to perform, but there was "no significant impact" determined as a result of rebuilding and constructing on that site. 
Importance of and effects on existence and populations of animals, plants, and avian species is discovered through inventory, and through developing a series of goals and objectives for managing those populations. The interaction of animals, plants, and avian species with existing environmental amenities such as soil, water, and air quality is more complex than can possible be studied and described simply. However, with a series of known and documented populations, and a series of goals and objectives, effects of construction, planting, and other operations can be tailored and managed to sustain, enhance, and develop populations of these species.

\section{Chapter 6 - Risk Assessment and Risk Strategies}

A significant body of literature exists about understanding and management of risk as related to sustainability issues Efroymson, et al., (2004) investigated an ecological framework for assessing risk from environmental degradation. From an environmental perspective, the field of sustainability risk management permits investigation of human concern about issues such as environmental change and the impact of manufacturing and industry on living populations. Although regulatory risk continues to be in the forefront of major business decisions, sustainability risk is now in the forefront. If regulatory risk concentrates on discovery of issues that may not be in compliance with laws and rulemaking, sustainability risk includes investigation of how enhancements of certain environmental amenities might be achieved, and what the cost of attaining these goals might be.

Thus, sustainability risk assessment accomplishes two things. First, it permits assessment of the level of over-compliance or extent of exceeding environmental compliance of any number of environmental amenities, using any of a number of environmental indicators. Second, it develops a cost structure that needs to be understood so that business decisions can be made of the cost of that overachievement. Since many environmental amenities arise from normal day-to-day operations, they are not necessarily included in a firm's production function. Economic sustainability and sustainable risk assessment are therefore jointly examined.

Businesses today need to integrate sustainability and risk management fully into their strategy not only to minimise ( $\mathrm{sic}$ ) potential losses but also to exploit new business opportunities arising from the sustainability agenda. These may include new products and services to meet developing sustainability needs, new technologies to improve sustainability or risk performance, or new business models to access and develop emerging markets and support the creation of sustainable communities (Arthur D. Little, 2009).

\section{Chapter 7 - Life Cycle Assessment with Life Cycle Inventory}

Life cycle assessment means examining the entire scope of operations from "cradle-to-grave" in order to understand the ecological mass balances through identification of all inputs and outputs through the entire stage of production, and use. This permits identification of environmental benefits and costs, and eventually permits identification of the economic costs and returns. 
There are several parts of a life-cycle analysis, but the two major functional parts are a life-cycle inventory, and the life-cycle interpretation (European Commission, 2010). The modeling aspects require a more in-depth discussion than this paper permits, but modeling decisions have major impacts on the kinds of data to be inventoried at the outset. Each particular project will dictate the modeling approach, and thus the inventory, and the eventual assessment and subsequent interpretation.

After the modeling decision types are decided upon, the mechanistic investigation and inventory of the life-cycle components requires an interdisciplinary team of researchers, from economists, to engineers, sometimes trained in specific disciplines of study (i.e. soil scientists, benthologists). Provided the life-cycle assessment is performed with a great deal of rigor and organization, tracking of the changes and monitoring of the progress across multiple years becomes easy. A simple example of the inventory process is shown in Figure 7-1. This process is perhaps multifunctional with several inputs and outputs (shown as product A and co-products B).

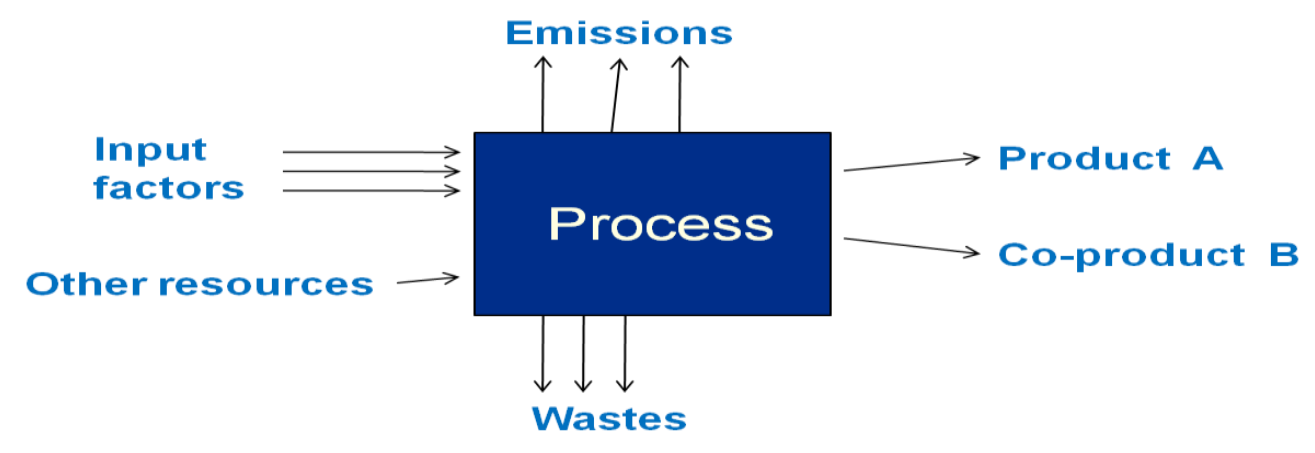

Figure 7-1. Multifunctional process showing several inputs in the form of resources consumed, in addition to several product outputs A and B (ILCD, 2010, page 73).

Interpretation of the life cycle assessment will provide an understanding of the inventory model and will therefore allow recommendation of changes based on improvement of the inventory to achieve stated goals and objectives for the sustainability plan. The assessment also allows comparison to other life-cycle assessments and allows derivation of robust conclusions and recommendations (ILCD, 2010).

The idea of a performing a life-cycle assessment has many benefits in developing an understanding of NEPA compliance, understanding risk determination and risk-assessment, as well as measuring achievement of sustainability goals. Life-cycle assessments are not inexpensive, and can be very time-consuming. But to truly understand all facets of every part of the environmental sustainability picture for resource supply for any industrial process, life-cycle assessments are required. 


\section{Chapter 8 - Role of National Environmental Policy Act (NEPA)}

The National Environmental Policy Act (NEPA) was enacted in 1970 after concerns about ecology, wildlife, and the general environmental health arose due to several circumstances. Several reports dating to the Eisenhower administration as well as the publishing of Rachel Carson's Silent Spring served as partial catalysts. NEPA contains three sections: 1) a declaration of policies and goals; 2) establishment of enforcement provisions for federal agencies; and 3) establishment of a Council on Environmental Quality in the Executive Branch.

The NEPA process consists of evaluating all environmental effects of a federally funded project including any of a number of potential alternatives. The goal of the process is to determine whether there are significant findings to develop an Environmental Impact Statement (EIS). The process is characterized by determining whether the proposed action (building a facility, or planting crops) is covered under the NEPA regulatory process; preparation of an environmental assessment of Finding of No Significant Impact (FONSI); and preparation and writing of an EIS.

If the proposed project is not covered under NEPA, a categorical exclusion (CX) is determined that exempts the project due to "no significant impacts", or that the federal agency undertaking the project has determined previously that no significant impacts were present, perhaps through the understanding and use of a programmatic NEPA.

If a proposed action or project is determined to fall under NEPA jurisdiction, a written environmental assessment (EA) is used to determine if there are significant impacts on the environment. A FONSI may result from this written EA, and if there are found to be significant impacts, creation of an EIS is required.

The development of the EIS is a more detailed evaluation of environmental impacts, and has multiple components including public, other federal agency input, and a public comment period allows other special interest groups to provide opinion.

Although federally funded projects and dollars signal NEPA jurisdiction, absence of federal funding does not exempt a project from state NEPA processes. Every state through their respective state environmental regulatory agencies may actually be more restrictive and provide finite guidance than federal NEPA processes. In cases where federal funding is used, state NEPA processes and regulations are invoked as well.

For example, a typical state environmental regulatory agency takes fair and consistent enforcement actions to ensure compliance with a state's environmental laws and regulations in a manner that promotes the health and well-being of the state's citizens and protects its environment (TDEC, 2011). In addition, agencies offer assistance for complying with the law, monitor compliance and take enforcement action when necessary to assure compliance with environmental regulations in that state. 
Enforcement is a part of encouraging individuals, communities, businesses and industries to meet their environmental obligations. Enforcement serves a number of important goals such as returning violators to compliance and deterring misconduct in others, eliminating or preventing environmental harm, and preserving a level playing field for responsible companies that abide by the law (TDEC, 2011).

\section{Chapter 9 - Relating and Linking Environmental Compliance (NEPA) and Economic Sustainability}

We have investigated the ways in which our definition of environmental sustainability affects how we do business, and how we measure indicators of sustainability toward determining specific impacts on specific environmental variables. It is clear that in many cases, the positive and negative externalities created as a result of business decisions are not included in a firm's production function. Because of this, a simplistic idea would be to determine the flows of desired environmental amenities, and seek a way to maximize that flow given an economic constraint. This production function does not take into account the fact that the value of the positive and negative externalities are not determined, in addition to the fact that they are not part of the firm's production function. In industrial economics and management, we assume that a firm is a profit maximizing entity, whose production function is of the form:

\section{1) Max a1;a2;::;;an R(a1; a2; ::; an) - C(a1; a2; ::; an)}

Figure 9-1. Profit Maximizing Function.

where:

a is a series of actions a firm undertakes

$\mathrm{R}(\mathrm{a})$ is a function of revenue streams from the actions, and

$\mathrm{C}(\mathrm{a})$ is a function of costs associated with those actions.

If the firm seeks to maximize profits subject to a series of cost constraints, the equation in Figure 9-1 demonstrates the nature of the firm's behavior in reaction to technologies, production input costs, and output prices.

Alternatively, if it is assumed there are multiple benefits arising from a firm's actions, there appears to be a more rigorous multiple benefits function and matrix as follows: 


\section{2) $\operatorname{Max} \Sigma(\alpha \ldots \eta)^{t}$}

\section{subject to: $\Sigma$ minimum level $\pi$}

\section{$\Sigma$ minimum $\alpha \ldots \beta$}

\section{$\Sigma$ minimum y}

Figure 9-2. Multiple Benefits Maximization Function.

where:

$(\alpha \ldots y)^{t}$ is a series of quantifiable environmental amenities or ecosystem services received over time $\mathrm{t}$,

$\pi$ is profit or net revenue as a floor,

$\alpha \ldots \beta$ are input factor and costs of production, and

$\mathrm{y}$ is a minimum yield permissible (floor) (Calinescu, et al., 2007)

Proposing this complex maximization function allows three things to happen immediately and causes at least one complication. First, it recognizes other possible motivations to be modeled than simply maximizing monetary profit. Second, it recognizes specific environmental parameters that are quantified to be measured over time. Third, it suggests that a firm must maintain a minimum level of profits to remain in business, and does not permit the level of environmental amenities (the flow of environmental goods and services provided by a particular action) to fall below a certain level.

The complications come in two forms. No longer can the profit maximization algorithm for solving this new function Figure 9-2 be simplistically determined. The quantitative measure of the environmental amenity(s) must be translated into economic values so that the overall profit level above which the firm must sustain is retained. It is this valuation of environmental amenities that consumes an incredibly voluminous body of recent literature and continues to be controversial. It is controversial because there are use- and non-use values for environmental amenities, a plethora of methods and modeling efforts to determine those values, and the ultimate values decided upon are contentious. There are arguments regarding the value of the amenity and controversy as a result of methods of valuation derived from damage assessment alone (U.S. EPA, 1987, and NOAA, 2011). For example, Section 301(c) of Comprehensive Environmental Response, Compensation and Liability Act (CERCLA) requires promulgation of regulations for the assessment of damages for injury to, destruction of, or loss of natural resources resulting from a discharge of oil or release of a hazardous substance. The responsibility for this rulemaking was delegated to the U.S. Department of the Interior (DOI) by the President in 
Executive Order 12580 (January 23, 1987). This is a completely separate issue from determining values from mere existence of a natural resource or environmental amenity. Other use valuation measurements come into play here.

If there were projections of the result of calculating the dynamic and multiple benefits maximization function in Figure 9-2, a possible outcome might be demonstrated in Figure 9-3. This graph demonstrates the flux of measured amenity levels for several variables over time. Although this contrived graph shows only a few environmental amenity levels, it does show that the measure of these amenities over time is critical to understanding their life-cycle in any particular season. It also shows the necessity of drilling down to the specific species being considered, whether it is a greenhouse gas emission (nitrous oxides (NOx), or avian species (brown-headed cowbirds).

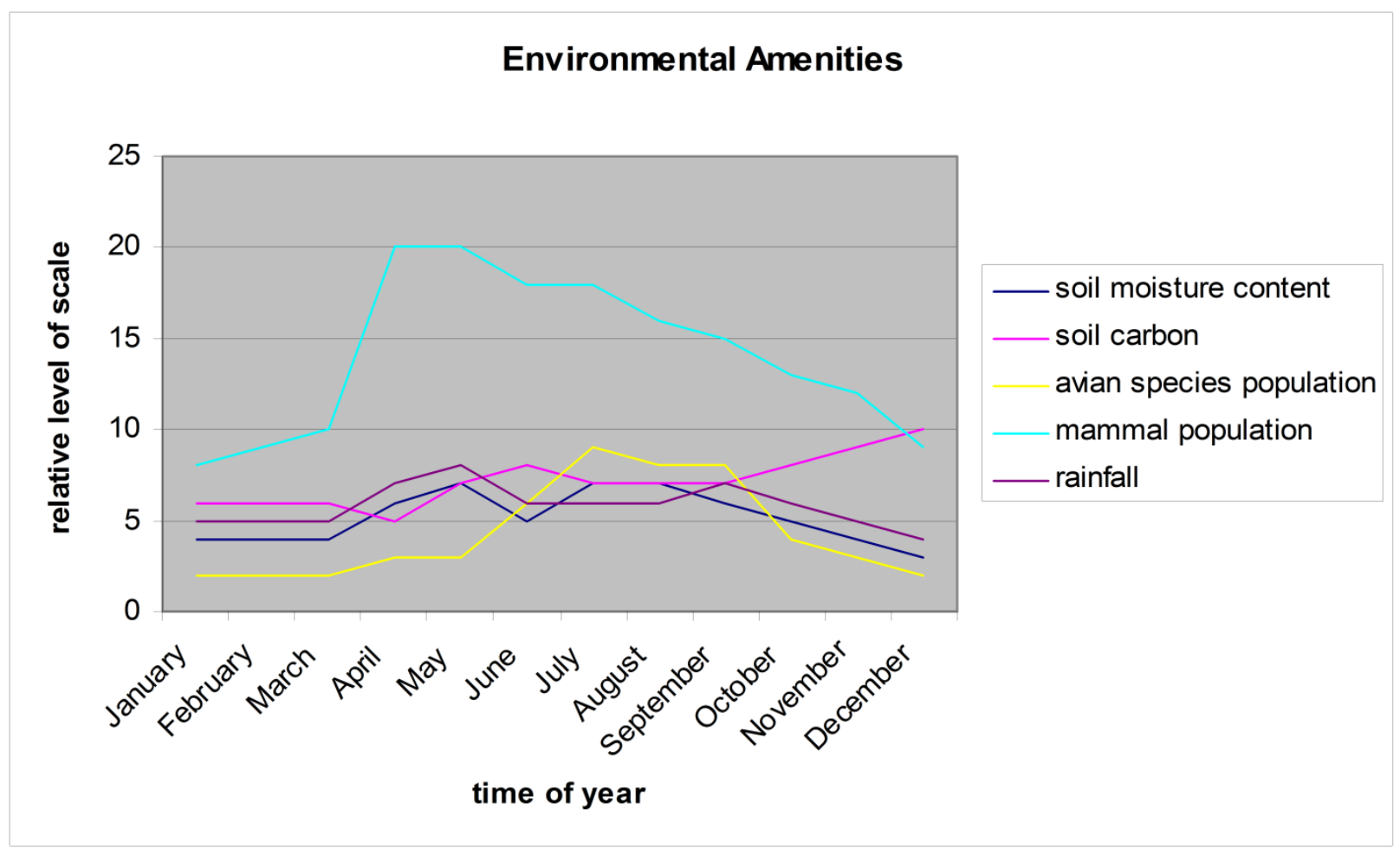

Figure 9-3. This figure demonstrates the relative values over time as a result of dynamic modeling of a specific set of environmental amenities. This may be enhanced by specifying a geographic region or scale for inventory. 


\section{Chapter 10 - Results and Discussion}

This paper summarizes the complexity of the process of determining environmental sustainability effects as a result of providing a renewable biomass supply. Although the framework for scientific investigation is much larger than described here, the expansion to include end-use of potential co-products, as well intense scrutiny of the management of the biomass supply from farm-gate to the biorefinery is possible. Figure 10-1 demonstrates this broader framework. From left to right in the diagram, we have concentrated on the biomass production areas and the biorefinery footprint. Throughout this pictorial flow, it is obvious that the series of data collected for an LCA inventory may be as complex as required to answer the resource sustainability effects questions for which answers are desired. The individual environmental benefits and costs may be determined, but to determine sustainability of the system requires that environmental sustainability goals be determined a priori.

In summary, six things are required for an analysis. First is a definition of the sustainable resource supply goals for environmental sustainability from a corporate decision and riskanalysis perspective. This step includes identifying specific environmental amenities to model and track. Second is a definition of the geographic extent of the study area. Third is establishing initial baseline values for specific environmental amenity levels (the life-cycle inventory, and life-cycle assessment and interpretation). In this step, evaluation of the bounds of measures for each amenity to include published requirements for minimum or maximum standards under current rules and regulations is required. In addition, establishment of internal goals for a particular attribute should be determined if not covered by laws and regulations. Fourth is the economic determination of expected profit or return on investment of the business decision. Fifth is the evaluation of the environmental trade-offs in a natural resource sense which leads to the economic valuation of those amenities which will be incorporated in the business's production function. Finally, a continual monitoring over time will determine any changes in the levels of amenities provided. 


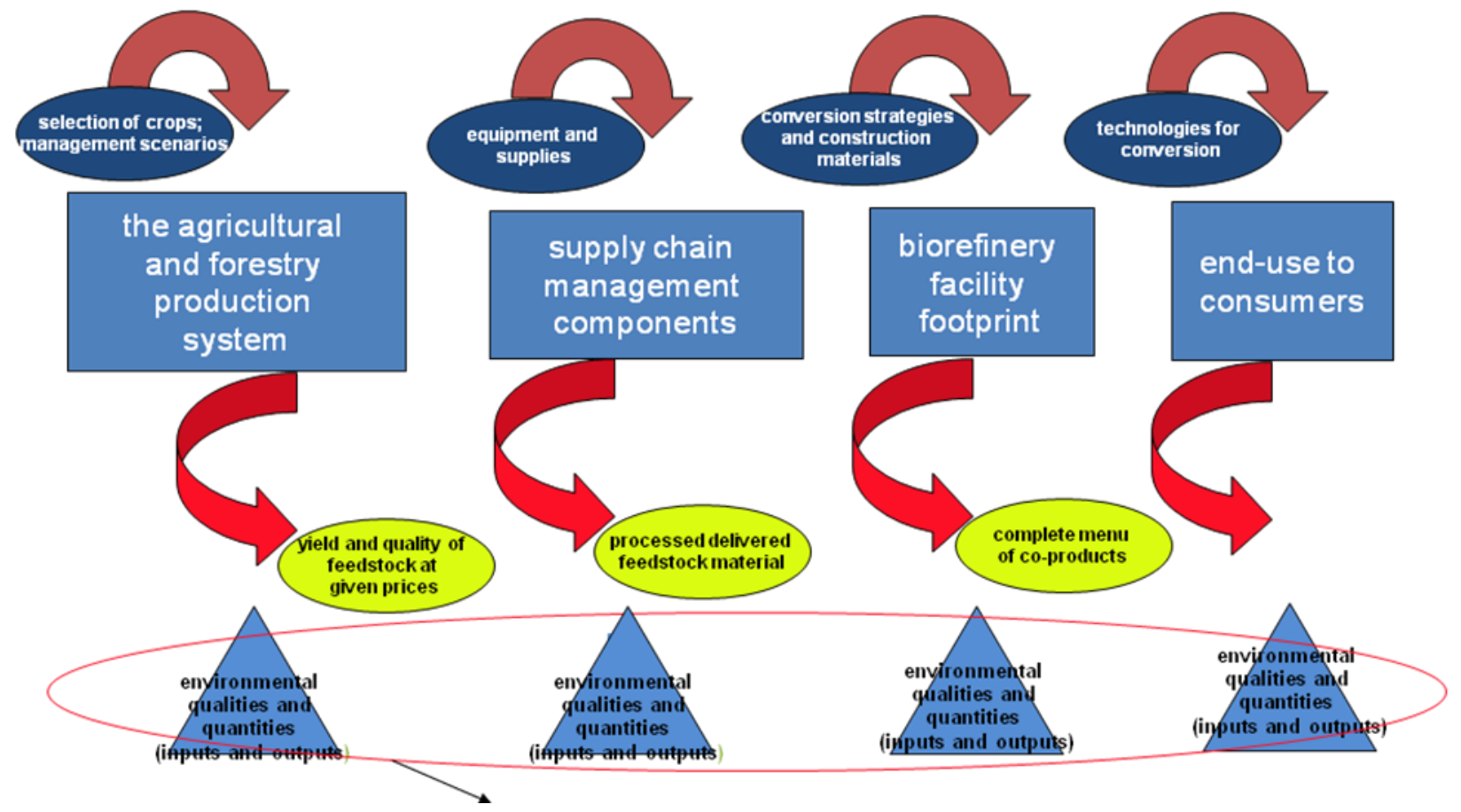

Figure 10-1. Scope of the measurable attributes of environmental quality and quantity in an end-to-end biorefinery observation. The red circle describes the focus of the environmental sustainability measures to include water, air, soil, and species population and diversity qualities.

\section{Chapter 11 - Further Research}

The next logical step is to select a geographic location for a biorefinery, along with a series of feedstocks to use. This necessarily dictates that a certain technology for biorefinery conversion is selected and that material balances, and process flow diagrams are understood and validated.

Perhaps another more global consideration might be the replicability of the biorefinery facility, the scalability of the proposed plant, and the geographic distribution of both biorefineries, and feedstock procurement and production locations.

If the end result ended up being the preliminary documents in support of programmatic NEPA, it would be the best possible outcome. If the remaining EIS issues uncovered pointed to a more project-by-project investigation, then the enumeration of these points would be valuable to corporate, state, and federal decision makers.

Refining the definition of certain socioeconomic and environmental indicators and their proxies would follow on logically, as a tighter specification of the kinds and types of variables, and their subsequent effects would be known. 


\section{Chapter 12 - References}

Arthur D. Little. 2009. http://www.adl.com/s-sustainability-risk.html.

Bot, Alexandra, and Jose Benites. 2005. The Importance of Soil Organic Matter: Key to Drought-Resistant Soil and Sustained Food Production. FAO Land and Plant Nutrition Management Service, Food and Agriculture Organization of the United Nations, Rome.

Brady, N. C. 1974. The Nature and Properties of Soils. New York: Macmillan Publishing Co.

Brundtland Commission Report. 1987. Our Common Future. Report of the World Commission on Environmental and Development. Published as Annex to General Assembly document A/42/427, Development and International Cooperation: Environment August 2, 1987.

Calinescu, et al., 2007. Maximizing a Submodular Set Function subject to a Matroid Constraint. Conference: Integer Programming and Combinatorial Optimization - IPCO , pp. 182-196, 2007

Council on Environmental Quality (CEQ). 2003. "Modernizing NEPA Implementation: The NEPA Task Force Report to the Council on Environmental Quality" (Sept. 2003). http://ceq.hss.doe.gov/ntf/report/finalreport.pdf

Virginia H. Dale, Rebecca A. Efroymson, Keith L. Kline, Matthew H. Langholtz, Paul N. Leiby, Gbadebo A. Oladosu, Maggie R. Davis, Mark E. Downing, Laurence M. Eaton, and Michael R. Hilliard. In process, Indicators to support assessment of socioeconomic sustainability of bioenergy systems.

Dale, Virginia, et al. 2010. Hypoxia in the Northern Gulf of Mexico. Springer Series on Environmental Management, Volume 41.

Data.gov, 2011. http://www.data.gov/.

Efroymson, R.A., Carlsen, T.M., Jager, H.I., Costova, T., Carr, E.A., Hargrove, W.W., Kercher, J., and Ashwood, T.L. 2004. Toward a Framework for Assessing Risk to Vertebrate Populations from Brine and Petroleum Spills at Exploration and Production Sites. Landscape Ecology and Wildlife Habitat Evaluation: Critical Information for Ecological Risk Assessment, Landuse Management Activities, and Biodiversity Enhancement Practices, ASTM STP 1458, L. Kapustka, H. Galbraith, M. Luxon, and G.R. Biddinger, Eds., ASTM International, West Conshohoken, PA.

Environmental Canada, 2011. http://www.environment.gov.ab.cal. The use of these materials by Mark Downing is done without any affiliation with or endorsement by the Government of Alberta. Reliance upon Mark Downing's use of these materials is at the risk of the end user. 
Environmental Protection Agency, 2003. Six Year Review, Chemical Contaminants, Health Effects Technical Support Document. EPA Office of Water, Office of Science and Technology. EPA 822-R-03-008.

Environmental Protection Agency. 2008. Clean Air Act. http://www.gpo.gov/fdsys/pkg/USCODE-2008-title42/pdf/USCODE-2008-title42chap85.pdf.

EPA. 2012. http://www.epa.gov/lawsregs/laws/nepa.html.

European Commission - Joint Research Centre - Institute for Environment and Sustainability. 2001. International Reference Life Cycle Data System (ILCD) Handbook - General guide for Life Cycle Assessment - Detailed guidance. First edition March 2010. EUR 24708 EN. Luxembourg. Publications Office of the European Union.

Executive Order 12580 of Jan. 23, 1987. Federal Register: appears at 52 FR 2923, 3 CFR, 1987 Comp., p. 193.

Fiorino, Daniel J. 1989. Environmental Risk and Democratic Process: A Critical Review. Columbia Journal of Environmental Literature. 14 (501).

Glanz, J. 1995. Saving our soil: solutions for sustaining earth's vital resource. Boulder, USA,Johnson Printing.

ILCD, 2012. http://www.buildup.eu/publications/9100.

Joint Research Center - European Commission. 2010. ILCD Handbook - General guide for Life Cycle Assessment.

McBride, Allen C., Virginia H. Dale, Latha M. Baskaran, Mark Downing, Laurence M. Eaton, Rebecca A. Efryomson, Charles T. Garten, Jr., Keith L. Kline, Henriette I. Jager, Patrick J. Mulholland, Esther S. Parish, Peter E. Schweizer, and John Storey. 2011. Indicators to support environmental sustainability of bioenergy systems. Ecological Indicators 11(2011) 1277-1289.

MN DNR. 2012. http://www.dnr.state.mn.us/eco/ereview/index.html.

NOAA - National Oceanic and Atmospheric Administration. 2011. http://www.darrp.noaa.gov/about/nrda.html.

Perlack, Robert, Lynn Wright, Anthony Turhollow, Robin Graham, Bryce Stokes, and Donald Erbach. 2005. Biomass as Feedstock for a Bioenergy and Bioproducts Industry: The Technical Feasibility of a Billion Ton Annual Supply. U.S. Department of Energy and U.S. Department of Agriculture. Oak Ridge National Laboratory ORNL/TM-2005/66. http://feedstockreview.ornl.gov/pdf/billion_ton_vision.pdf 
San Francisco Department of Public Health, 2010.

http://www.sfphes.org/publications/PHES_publications.htm; Environmental Health Section, Program on Health Equity, and Sustainability.

Smith, Richard A., Richard B. Alexander, and M. Gordon Wolman. 1987. Water Quality Trends in the Nation's Rivers. Science 27, March 1987, Vol. 235 no. 4796 pp. 1607-1615, DOI: 10.1126/science.235.4796.1607.

Suter, Glenn W. II, and Lawrence W. Barnthouse. 1993. Ecological Risk Assessment. CRC Press, LLC., Boca Raton, FL.

Swanson, H.A., and Baldwin, H.L. 1965. A Primer on Water Quality. U.S. Geological Survey.

Texas A\&M University, 2003. The Partnership for Environmental Education and Rural Health (PEER). Sponsored by National Institute of Environmental Health Sciences. http://peer.tamu.edu/curriculum_modules/

University of Minnesota, 2001. Twelve Indicators to Measure Soil Quality. Corn and Soybean Digest, Denise Williams, July 17.

Tennessee Department of Environment and Conservation, 2011. http://www.tn.gov/environment/permits/sops.shtml\#nat.

Tisdale, S. L. and W. L. Nelson. 1975. Soil Fertility and Fertilizers. 3rd ed. New York: Macmillan.

U.S. Department of Interior, 2011.

http://www.epa.gov/superfund/programs/nrd/links.htm\#executive.

U.S. Environmental Protection Agency, 1987. http://www.epa.gov/superfund/policy/cercla.htm.

U.S. DOE. 2011. U.S. Billion Ton Update: Biomass Supply for a Bioenergy and Bioproducts Industry. R.D. Perlack and B. J. Stokes (Leads), ORNL/TM-2011/224. Oak Ridge National Laboratory, Oak Ridge, Tennessee. 227p.

Wood Buffalo Environmental Association, 2011. http://environment.alberta.ca/02047.html. Wright, Lynn. 27 March 2012: Personal communication. Oak Ridge National Laboratory. 
Appendix A - The BioEnergy Cycle 


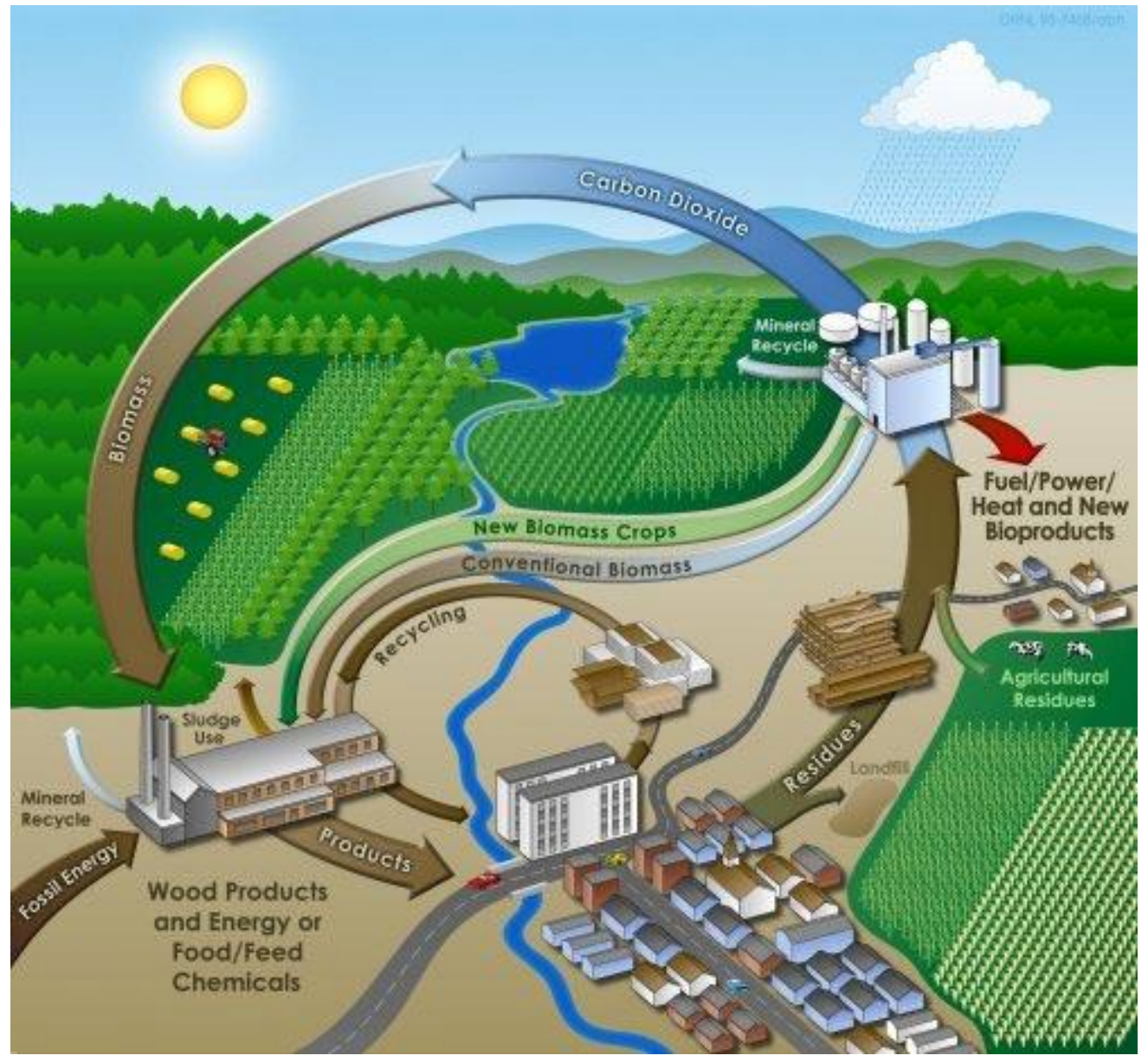

ORNL 98-746B/abh

Bioenergy is produced in a cycle. Sustainable use of natural energy mimics the earth's seasonal variations and minimizes the emission of pollutants into the air, rivers and oceans. Most of the carbon to create it is taken from the atmosphere and later returned to the atmosphere. The nutrients to create it are taken from the soil and later returned to the soil. The residues from one part of the cycle form the inputs to the next stage of the cycle.

Carbon dioxide $\left(\mathrm{CO}_{2}\right)$ is withdrawn from the atmosphere by the process of plant growth (photosynthesis) and converted into vegetation biomass (trees, grasses, and other crops). Harvested biomass, together with forestry and crop residues, can be converted into building materials, paper, fuels, food, animal feed and other products such as plant-derived chemicals (waxes, cleaners, etc.). Some crops may be grown for ecological purposes such as filtering agricultural run-off, soil stabilization, and providing habitat for animals as well as bioenergy. The solid biomass processing facility (represented by the factory building at the bottom left) may also generate process heat and electric power. As more efficient bioenergy technologies are developed, fossil fuel inputs will be reduced. Organic by-products and minerals from the processing facility may be returned to the land where the biomass grew, thereby recycling some of the nutrients such as potassium and phosphorus that were used for plant growth. 
Selected residues from the town may be combined with forestry and crop residues, animal wastes, and biomass crops to provide the feedstocks for a different type of biomass processing (represented by the factory at the top right). This new biomass processing facility (or biorefinery) could make a range of products - fuels, chemicals, new bio-based materials, and electric power. Animal feed could be an important co-product of some processes. Such biomass processing facilities would use efficient methods to minimize waste streams and would recycle nutrients and organic materials to the land, thereby helping to close the cycle.

Biomass products (food, materials, and energy) used by the human population are represented by the town at the bottom of the diagram. The residues from the town (scrap paper and lumber, municipal refuse, sewage, etc.) are subject to materials and energy recovery, and some may be directly recycled into new products.

Throughout the cycle, carbon dioxide from biomass is released back into the atmosphere-from the processing plants and from the urban and rural communities - with little or no net addition of carbon to the atmosphere. If the growing of bioenergy crops is optimized to add humus to the soil, there may even be some net sequestration or long-term fixation of carbon dioxide into soil organic matter. The energy to drive the cycle and provide for the human population comes from the sun, and will continue for many generations at a stable cost, and without depletion of resources.

For additional information, contact the Bioenergy Feedstock Development Program, Oak Ridge National Laboratory, P.O. Box 2008, Oak Ridge, TN 37831-6422, (865) 576-8140 
This page unintentionally left blank. 